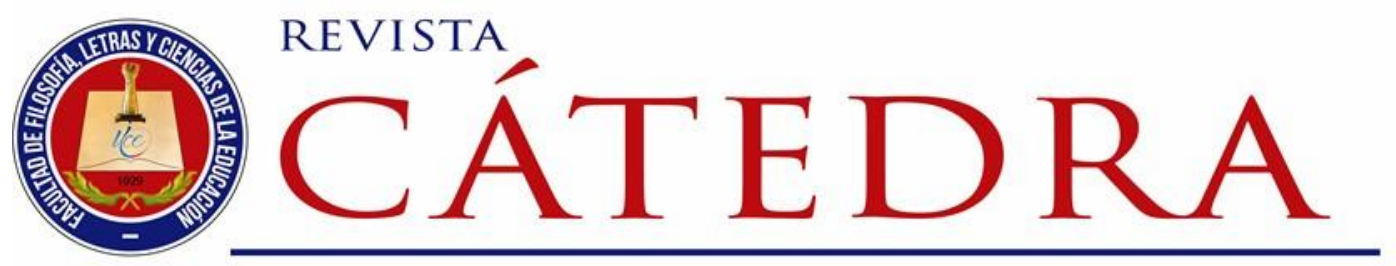

\title{
Percepciones sobre el concepto nación: diagnóstico a través del aporte literario de Juan León Mera yla propuesta del decoloniaje
}

\section{Perceptions about the concept of the nation: diagnosis through the literary contribution of Juan León Mera and the decolonial proposal}

\author{
Glenda Viñamagua-Quezada \\ Universidad UTE, Quito, Ecuador \\ glenda.vinamagua@ute.edu.ec \\ https://orcid.org/0000-0002-9514-1855
}

(Recibido: 01/04/2019; Aceptado: 15/04/2019; Versión final recibida: 02/05/2019)

Cita del artículo: Viñamagua-Quezada, G. (2019). Percepciones sobre el concepto nación: diagnóstico a través del aporte literario de Juan León Mera y la propuesta del decoloniaje. Revista Cátedra, 2(2), 39-54.

\section{Resumen}

De la labor literaria así como del arte en general es relevante su postura crítica, que surge como una respuesta a los acontecimientos que se manifiestan a nivel social con el fin de cuestionar el sistema establecido y conseguir transformaciones. Esta labor se comprende como el compromiso que deberían asumir los intelectuales. En este caso se hará un acercamiento a la postura de Juan León Mera con respecto a la creación y comprensión del concepto de nación a través de la composición de la letra del Himno Nacional del Ecuador. Se expondrá desde el enfoque de teorías como el decoloniaje y el corazonar, una alternativa de espacios inclusivos, que se asumirán como un reto para la sociedad al ser abordados y difundidos desde la educación. El objetivo del presente artículo es reflexionar en la construcción de la idea de nación a partir de la exclusión del otro y en el decoloniaje como una forma de contrarrestar este pensamiento. Para ello se ha realizado una investigación bibliográfica documental desde una óptica hermenéutica. El aporte de esta investigación radica en enfocar a la teoría del decoloniaje como una alternativa para despertar la

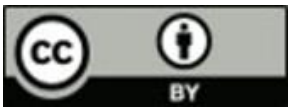


conciencia crítica hacia la reivindicación en comunión con la alteridad a través del trabajo literario y educativo.

Palabras clave

Alteridad, coloniaje, decoloniaje, intelectuales, otredad, nación

\section{Abstract}

From the literary as well as the art in general, its critical position is relevant, arising as a response to the events that manifest at the social level in order to question the established system and achieve transformations. This work is understood as the commitment that intellectuals should acquire throughout history. In this case, an approach will be made to the position of Juan León Mera regarding the creation and understanding of the concept of nation through the composition of the lyrics of the National Anthem of Ecuador. It will be exposed from the theory approach such as decolonialism and heart, an alternative of inclusive spaces, assumed as a challenge for society to be approached and disseminated from education. The objective of this article is to reflect on the idea of nation and its construction from the exclusion of the other due to the process of colonization as a way to counteract this thought; for this a documentary bibliographic research has been carried out from a hermeneutical perspective. The contribution of this research lies in focusing on decolonial theory as an alternative to awaken awareness towards the claim in communion with otherness through literary and educative work.

\section{Keywords}

Alterity, colonialism, decoloniage, intellectuals, nation, otherness.

\section{Introducción}

El concepto de nación se encuentra en reinvención constante, si bien su inicio obedece a procesos históricos determinados, también es cierto que quienes acuerdan y acomodan su enfoque son los grupos minoritarios, lo que da paso a la marginación de las periferias en el proyecto de nación. Debido a la rigidez con la que se pretende articular este concepto, al vincularlo solamente con algunos elementos que privilegian a las minorías frente al otro, Bhabha (2002), indica "La crítica de Fanon a las formas fijas y estables de la narrativa nacionalista hacen imperativo cuestionar teorías del tiempo vacío horizontal y homogéneo de la narrativa de nación" (pág. 189)

Así, los grupos marginados de la idea de nación deberán sujetarse a un proceso de anulación cultural y de adoctrinamiento para ser reconocidos como parte de esta, debido a que este concepto se estructuró a partir de la inclusión y de la exclusión para lograr una identidad común. Este enfoque choca con las diversidades que conforman los grupos humanos, de manera que se ha encontrado con muchas críticas. Por lo que, Mellado (2008) cuestiona "Una nación, entonces, no puede pensarse en términos de clausura, como algo que es, sino que debería considerarse como una figura en tránsito constante, in media res, como algo que está siendo y, a la vez, se está haciendo continuamente" (pág. 31).

La mirada colonial para construir el concepto de nación desplaza la alteridad y valida la visión de los grupos de poder. En el contexto ecuatoriano se valora la labor literaria de Juan León Mera y su postura visionaria con respecto al indígena en la formación de la nación, luego del proceso de invasión española. Cabe señalar sin embargo, los condicionamientos 
tanto religiosos como idiomáticos que se impuso al indígena para integrarlo a la nación ecuatoriana.

Estos condicionamientos dan cuenta de la dependencia a la corona española, que aún pervivía en la naciente república, dependencia que aún se mantiene en la actualidad. Esta atadura todavía subsiste con otro tipo de colonizadores y se la conoce como colonialidad del poder, de la que se desprenden la colonialidad del ser, del saber y del pensar.

Es preciso aclarar que la colonialidad que imperó en la idea de nación ecuatoriana fue el concepto de raza; término que originó una cultura despojada que en cierta medida se hizo visible con el trabajo de Mera, y pese a los cuestionamientos que pudiesen existir con respecto a su postura sobre la cultura indígena, su aporte fue vital y visionario para el reconocimiento de la diversidad debido al contexto en el que surgió su obra. Pues incluso en este siglo, como lo indica Quijano (2000)

La estructura de poder fue y aún sigue estando organizada sobre y alrededor del eje colonial. La construcción de la nación y sobre todo del Estado-nación han sido conceptualizadas y trabajadas en contra de la mayoría de la población, en este caso, de los indios, negros y mestizos. La colonialidad del poder aún ejerce su dominio, en la mayor parte de América Latina, en contra de la democracia, la ciudadanía, la nación y el Estado-nación moderno (pág. 237).

Se plantea así el decoloniaje, teoría germinada en América, antes conocida como Abya-Yala ${ }^{1}$, como un lugar de convivencia a partir de la integración de la diversidad cultural, donde la alteridad abre paso a un abanico de diferentes formas de vida posibles en la idea de nación. Dentro de este panorama el escritor asumirá el reto de narrar una nueva historia con el protagonismo de las periferias, mientras que el docente cultivará el pensamiento crítico desde las aulas a partir de pensamientos insurgentes como el Corazonar, que Guerrero (2010) describe como:

CORAZONAR no es simplemente un neologismo, sino que implica pensar un modo de romper la fragmentación que de la condición humana hizo la colonialidad del poder, pues, desde la racionalidad colonial de occidente, RAZONAR ha sido el centro de la constitución de lo humano, ya desde un punto de vista semántico la sola palabra connota la ausencia de lo afectivo, la RAZÓN es el centro, y en ella la afectividad no aparece ni siquiera en la periferia (pág. 40).

Este pensamiento se fundamenta en la filosofía andina, donde prevalece el pensar con el corazón, así se comprende al ser humano como un sistema integral y equilibrado que valora el bienestar común frente al deseo individual. En contraparte de la modernidad capitalista que germinó en América a partir del colonialismo europeo, donde predomina el razonar que antepone al individuo frente al grupo.

\footnotetext{
${ }^{1}$ Abya Yala, que significa Tierra Madura, Tierra Viva o Tierra en Florecimiento, fue el término utilizado por los Kuna, pueblo originario que habita en Colombia y Panamá, para designar al territorio comprendido por el Continente Americano. De acuerdo con el momento histórico vivido, se referían a este territorio de diferente forma: Kualagum Yala, Tagargun Yala, Tinya Yala, y Abya Yala, siendo este último el que coincidió con la llegada de los españoles (Carrera B. y Ruiz Z., 2016, pág. 17)
} 
Con respecto a la metodología, este artículo cumple con una investigación bibliográfica documental que emplea el método hermenéutico, para realizar un recorrido por el proceso histórico que provocó el surgimiento de la nación ecuatoriana, la figura del indígena y el papel de Juan León Mera dentro de este contexto al escribir el Himno Nacional del Ecuador. En la propuesta se aborda al decoloniaje como una fórmula que denuncia el coloniaje persistente "como un proceso de dominación que aún no ha concluido, sino que se ha encubierto por un fenómeno intrínseco a la misma colonialidad: la modernidad" (Guerrero, 2010, pág. 25).

\section{Principales planteamientos teóricos para la inclusión al concepto de nación}

Concretar un significado de nación es una tarea compleja, más aún cuando se observa la realidad que se vivió en las colonias españolas en América. Espacio donde la exclusión cultural que mantenía en la periferia al otro y lo disminuía frente a la hegemonía dominante fue un hecho que configuró la historia y lo heredó el presente. Pensar que nación y cultura son términos inherentes deja fuera la integración de la diversidad en un solo proyecto, de manera que para pertenecer a una nación se deberá anular la propia cultura y asimilar la que impongan los grupos de poder para sentirse dentro de ella y amparados por ella. Al respecto, Gellner (2001) aclara que "el hombre quiere estar políticamente unido a aquellos, y solo a aquellos, que comparten su misma cultura" (pág. 80). La finalidad de esta condición es reafirmar espacios puristas que ubican, categorizan y desechan, en función de conseguir que las sociedades conserven los roles históricamente establecidos.

Estos conceptos tradicionalmente transmitidos dejan en evidencia la marginación de los grupos minoritarios y su consecuente condicionamiento para que anulen su identidad cultural, condición sin discusión para ser aceptados como parte de la nación. Es necesario mencionar que estas minorías no son incluidas en plenitud pese a su sometimiento, en consecuencia, esta condición pasa a convertirse en una herramienta de dominio, al respecto Romano (1994) señala:

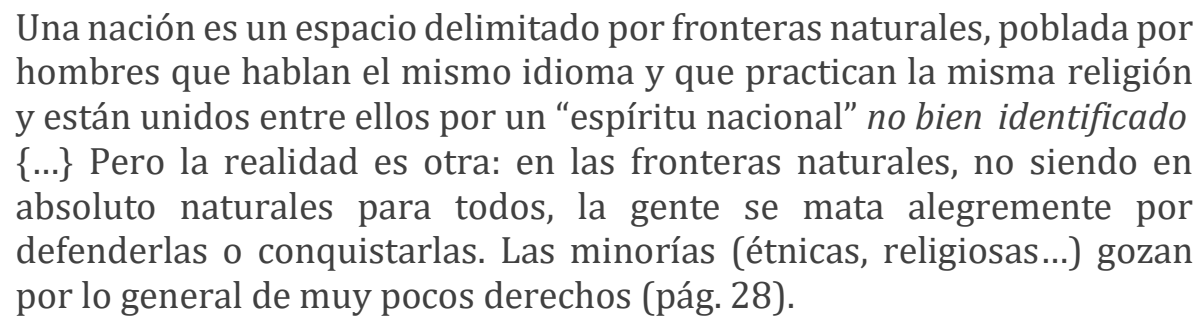

El concepto de nación obedece a una creación social que es útil para la perpetuación tanto de estados dominantes como de estados dependientes. Este concepto se difunde a través del uso de la educación como lo menciona Traverso (1998) "Sin embargo, todo el bagaje doctrinal, con marcado sesgo eurocéntrico, ha llegado a través de los textos de ciencias sociales a todas partes del planeta y ha contribuido a la universalización y reificación de toda esa teorización" (pág. 41). Así, hablar de nación solamente sería repetir ideas impuestas que se piensan y asimilan como propias en función de un discurso que apela tanto al intelecto como a la emoción.

La idea de nación se ajusta a los intereses de la oligarquía, a quienes Romano define como propietarios, grupos minoritarios cuyos roles dentro de la sociedad describe de la siguiente manera:

Licencia Creative Commons Atribución 4.0 Internacional (CC BY 4.0)

Revista Cátedra, 2(2), pp. 39-54, mayo-agosto 2019. e-ISSN: 2631-2875

https://doi.org/10.29166/catedra.v2i2.1655 
En 1830, el estado de Michoacán para definirlos (en función de las normas del censo para el ejercicio del derecho de voto) dice: Llamamos pues propietarios a los que tienen bienes raíces y a los que ejercen una profesión, como los jurisconsultos, los escribanos, los militares, los letrados, los fabricantes, los banqueros, comerciantes, agentes de cambios, artistas y otros que sobrellevan las contribuciones personales y las indirectas, y cuyos intereses se hallan íntimamente unidos con la subsistencia del gobierno (Romano, 1994, pág. 32).

Se describe de esta manera la ausencia de alteridad, el desconocimiento del otro dentro de una sociedad diversa, como ocurrió en las llamadas colonias en América para la construcción de una nación integradora y cuyos sesgos aún perviven. Queda en evidencia que las decisiones trascendentales para construir una memoria social históricamente han ignorado la voz de quienes fueron víctimas de "Una conquista violenta, sanguinaria, ciega, que condujo a la destrucción de otros pueblos poseedores de una cultura y una civilización en verdad superiores a los del grupo conquistador" (Romano, 1994, pág. 35).

Si bien hasta este momento se ha expuesto la no aceptación de la cultura externa frente a la interna, también es preciso indicar los conflictos que se generaban dentro del propio territorio. Pues a causa de la asimilación de este concepto, varios intereses, principalmente ligados a la supremacía y dominio no daban paso a la visibilización de diversas culturas en el constructo de nación y se pretendía anularlas.

El problema no es simplemente la "mismidad" de la nación como opuesta a la alteridad de otras naciones. Nos enfrentamos con la nación escindida, dentro de sí misma [itself] alienada de su eterna autogeneración, se vuelve un espacio significante liminar que está internamente marcado por los discursos de minorías, las historias heterogéneas de pueblos rivales, autoridades antagónicas y tensas localizaciones de la diferencia cultural (Bhabha, 2002, pág. 185).

Así, los intelectuales ligados al campo artístico, con la difusión de su pensamiento a través de su obra, visibilizan estas realidades ocultas para incluirlas en el concepto de nación, que emergía luego del desplazamiento de las colonias. Uno de estos intelectuales fue Juan León Mera, quien resalta la presencia de la cultura indígena y su importancia dentro del proyecto de nación ecuatoriana.

\section{Concepción de lo romántico y fundacional en un contexto histórico y geográfico}

La historia se teje bajo la visión de quienes tienen la voz para hablar de ella, y el presente también se va armando bajo la misma voz. Es preciso indicar que tras los intelectuales hay una maquinaria que se mueve, ya sea por su ideología o su acomodo, y de esta manera se crean momentos clave que quedan marcados como históricos.

El episodio que fue el marco para el inicio de la idea de nación se remite a la revolución francesa y al surgimiento de la edad moderna con su herencia nacionalista, matizados ambos espacios por conflictos y revolución. Esta revolución compromete a la iglesia que hasta entonces era un solo pilar, a la política que marca otra visión a partir de la revolución francesa, al campo del arte que deja de lado el paradigma neoclásico de la rigidez.

En este contexto surge el movimiento romántico, que señala una ruptura con el neoclásico, hablando netamente del romanticismo alemán o inglés. En América este movimiento está

Licencia Creative Commons Atribución 4.0 Internacional (CC BY 4.0)

Revista Cátedra, 2(2), pp. 39-54, mayo-agosto 2019. e-ISSN: 2631-2875

https://doi.org/10.29166/catedra.v2i2.1655 
más relacionado con la literatura fundacional, a cuya época corresponde el pensamiento de Juan León Mera.

\subsection{Inclusión de la cultura indígena en la idea de nación ecuatoriana}

La idea de nación surgió como un concepto moderno para dar soporte a los estados luego de hechos clave dentro de la historia universal. En este contexto, los intelectuales del siglo XIX se comprometieron a aportar en la construcción de la nación, de manera especial los intelectuales de América, quienes también se vieron influidos por los procesos de emancipación de la corona española. De tal manera que urgía en este continente reformularse un concepto de nación tanto desde la óptica del mestizaje como desde realidad indígena, y otorgarle legitimidad desde las letras.

En el recién constituido Ecuador, muchos intelectuales contribuyeron a dar forma a esta nación dentro del marco del Romanticismo americano, sin embargo uno de los aportes más significativos lo realizó Juan León Mera, no solamente por haber escrito el Himno Nacional, que sin duda constituye su principal contribución para la nación, sino por toda la trayectoria intelectual que lo llevó a concluir con este trabajo.

Entre sus aportes cuentan la traducción del kichwa al español de composiciones líricas, entre la que destaca el poema Atahualpa Huañui cuya autoría se concede a un cacique de Alangasí. En la labor de traducción de esta pieza, Mera muestra su compromiso con la causa indígena dentro de la idea de nación. En el cuadro que se presenta a continuación se transcriben versos seleccionados del poema en su versión original, además la traducción de Juan León Mera y las observaciones que hace Rodríguez Castelo sobre el alcance de la traducción.

\section{Atahualpa Huañui Kichwa}

8. Puyu puyulla

9. uiracuchami,

10 curita nishpa

11 Jundarircami.

12 Inca yayata

13 Japicuchishpa,

14 Siripayashpa

15 Huañuchircami.

\section{Atahualpa Huañui Traducción Juan León Mera}

como niebla espesa vinieron los blancos $\mathrm{y}$ de oro sedientos llenáronse aquí. al padre inca luego duros apresaron, tendiéronle en tierra, le hicieron morir.

\section{Notas sobre la traducción}

Con respecto a la
traducción de esta obra
lírica, Rodríguez
Castelo (s.f.) realiza un
análisis comparativo de
la métrica y la
intensidad que se
manifiesta en el poema,
tanto en su lengua




\section{Atahualpa Huañui Kichwa}

29 Mana llaquisha

30 Ñuca llactapi

31 Shucta ricushpa.

32 Turi cunalla

33 Tandanacuchun,

34 Yahuar pampani

35 Huacanacushum.

36 Inca yayalla,

37 Yanac pachapi

38 Ñuca llaquilla

39 Ricungui yari.

40 Caita yuyashpa

41 Mana huañuni,

42 Shungu llugshishpa

43 Causaricuni

\section{Atahualpa Huañui Traducción Juan León Mera}

¡como no abrumado he de estar de pena, viendo que mi patria de extraños es ya! juntémonos todos, hermanos, y vamos la tierra sangrienta de llanto a regar. desde el alto cielo, ¡oh inca, padre amado! nuestra amarga pena dígnate mirar. viendo tantos males, ¿no me he de morir corazón no tengo, ¿y aún puedo vivir?

\section{Notas sobre la traducción}

original como en la traducción y concluye: "Mera ha recogido golpeteo repetido, insistente, pero en modo alguno el sabor elegíaco del original quichua" (pág. 29)

Esta observación de Rodríguez Castelo manifiesta los límites que implica un ejercicio de traducción.

Cuadro 1. Versos de la elegía Atahualpa Huañui en Kichwa con la traducción de Juan León Mera (Rodríguez Castelo, S.F., págs. 25-26).

Los versos citados en el cuadro no responden a la totalidad del poema por lo que se los ha numerado según su orden original. El criterio de selección de estos versos obedece al hallazgo de términos que denuncian los estragos que provocó la invasión española, su consecuente coloniaje y el sentir del indígena. Se destaca la labor de traducción de Mera, al convertirse en difusor del pensamiento indígena a través de la lengua española.

El aporte de Juan León Mera como poeta fundacional es muy significativo desde el campo intelectual, pues influyó su visión del mundo para transmitir un concepto de nación. Esta idea que germinaba incluía la idea de pluriculturalidad, aunque de manera limitada, por los condicionamientos a los que se sometía a los indígenas para reconocerlos como parte de la nación ecuatoriana.

\subsection{Inclusión condicionada por motivos religiosos}

Se habla de la fundación de la nación americana como contraparte de lo europeo no como nación independiente. Por lo que se debía seguir otros caminos para lograr este objetivo, como la necesidad de incluir a las culturas indígenas (que en ese entonces se reconocía como una sola), pero esta inclusión no era gratuita. Juan León Mera consideró que los indígenas debían ser incluidos en el nuevo concepto de nación, pero para ello debían cristianizarse y hablar español, sin dejar de lado sus costumbres, idiomas y tradiciones, que se les permitía seguir practicando, pero solo dentro de sus espacios. Estas condiciones debían ser cumplidas para ser reconocidos como parte de la nación.

Este punto de vista de Mera muestra, en cierta medida, el carácter liberal que en algún momento lo caracterizó, antes de anexarse al pensamiento del presidente García Moreno de quien Pedro Moncayo dice "traidor a la Patria y a las repúblicas de Pacífico, monstruo atroz del que, no obstante, nada tiene que decir como legislador y hombre de Estado" (Buriano, 2009, pág. 201). Con respecto a García Moreno, Mera argumenta lo siguiente: 
Francamente, yo por naturaleza soy enemigo del cadalso, yo no lo quisiera ni aún para Urvina, pero sí me agrada que usted mande, aunque sepa fusilar, porque hay cosas que valen más que la vida de un revolucionario, cuales son la religión, la moral, la paz y demás intereses comunes en una nación (Vallejo, 2002, pág. 210).

La inclinación política de Mera y su intención de reivindicación al indígena en el proyecto de nación podrían comprenderse como un pluralismo condicional. Pluralismo que ponía de manifiesto su espíritu conservador y que además confirma los elementos que configuran al romanticismo ecuatoriano, como son los temas o problemáticas políticas, religiosas y sociales.

El tema religioso era tan relevante para Mera y para quienes pensaban en la nación en el siglo XIX, hasta el punto que algunos intelectuales indican que el Ecuador se formó en la iglesia, esta afirmación se confirma cuando, Mera (s.f) menciona "La historia política de las naciones, siempre (ha estado) eslabonada con la historia religiosa" (pág. 180).

Se percibe en Mera una intención de reivindicar al cristianismo, por la manera como se lo mpuso durante el proceso de invasión española. En su momento, Mera lo configura como un espacio que pueden compartirlo blancos, mestizos e indígenas, por lo tanto la fe católica debería ser uno de los requisitos para formar nación y ser ciudadanos, según la cosmovisión de Mera.

\subsection{Lo lingüístico y lo estético considerados como pilares de la nación}

Los intelectuales del siglo XIX, entre los que se incluye Mera, tienen un horizonte fundacional a más del proyecto estético, lo que es palpable, en el caso de Mera, en la creación de la letra del Himno Nacional del Ecuador. Así mismo se puede afirmar que toda su obra se orienta hacia visibilizar los componentes de la nueva nación ecuatoriana considerando la tradición kichwa ${ }^{2}$ tanto en su aporte estético en la literatura como por su estructura lingüística. Al respecto, Harrison (1996) menciona "Aunque Mera nunca propuso la adopción del quichua como idioma nacional, se observa, a través de sus ensayos, que sus ideas se basaban en el principio de que el idioma era una fuerza externa que influye en el pensamiento" (pág. 85).

Una de las propuestas de Mera fue la incorporación de palabras kichwa al léxico, para potenciar el castellano como lengua oficial de la nación, iniciativa que se refuerza cuando es nombrado miembro de la Real Academia de la lengua Española en 1872 (Harrison, 1996, pág. 88). Sin embargo también es preciso recordar el peso adoctrinador que tenía el dominio de este idioma "Mera pensaba que el idioma aborigen era de utilidad tan sólo para los grupos con un interés especial como los clérigos y los filólogos" (Harrison, 1996, pág. 119).

La valoración del kichwa para Mera obedecía a lo claro que era para él el hecho de integrar a los indígenas al proyecto de nación. Con la traducción de Atahualpa Huañui se estaría reforzando la idea de "transformar a Atahualpa en un ícono fundador da la nacionalidad

\footnotetext{
2 Kichwa es una de las 14 lenguas ancestrales del Ecuador, esta forma de escribirla es propia de las comunidades, mientras que la forma españolizada es quichua, por lo que se leerá quichua cuando se trate de citas, para conservar la escritura del texto original y kichwa en el resto del artículo.
} 
ecuatoriana y en cierto sentido, desplazar la mítica historia del Reino de Quito" (Prieto, 2010, pág. 304) aunque el afán en Mera solamente debió remitirse al reconocimiento de la influencia indígena en el proyecto mestizo de nación y no en sobreponer la representatividad de Atahualpa ante el Reino de Quito.

\section{El Himno Nacional como símbolo de la constitución de la nación}

Mera va fijando los cimientos de la estructura de nación a partir de la literatura, con sus estudios críticos y recopilaciones de las creaciones que se dieron hasta ese entonces. Dentro de su obra literaria, el tema moralizante y didáctico era muy importante en el proceso de pensar en nación, y el más significativo de ellos fue el Himno Nacional del Ecuador.

Acerca de ello es preciso mencionar que el Ecuador tuvo un himno propio, 30 años después de su formación, por la iniciativa de Juan León Mera. Este intelectual ambateño nació 10 años después de la Batalla de Pichincha, y en 1865 escribe el Himno Nacional. Cuatro años después Juan José Allende le musicaliza, y en 1870 Antonio Neumane escribe la música definitiva (Miño, 1995, págs. 156-157).

Todo el trabajo y trayectoria de Mera, se vio sintetizado en la creación del Himno Nacional en 1865, tema que le provocó muchos cuestionamientos debido a su posición con respecto a España y al proceso de coloniaje en el naciente Ecuador. Sin embargo de esta polémica no se logró que la letra del Himno fuera cambiada aunque para su musicalización sí fue sustituida la primera estrofa por la segunda.

Este conflicto se mantuvo hasta que en 1922, Pablo Arturo Suárez, médico ambateño, intenta poner fin a esta lucha, que evidenciaba aún en ese entonces un servilismo hacia España, Suárez dice "el himno nacional que tenemos traduce los sentimientos de nuestros antepasados y creo que debemos respetarlo" (Miño, 1995, pág. 157).

Sin embargo, el afán de cambio continúa y en 1923 el congreso presidido por Carlos Alberto Arroyo del Río delega en la academia de la lengua el cambio de la letra. La academia reúne a tres personas que tendrán a su cargo esta tarea: Juan León Mera Iturralde, hijo de Juan León Mera; Manuel María Pólit, arzobispo de Quito, Clemente Ponce, ministro de relaciones exteriores. De esta manera, la academia, la iglesia y la política desde su poder, debían decidir cómo resolver este conflicto (Miño, 1995, pág. 158).

Las medidas que toman son reemplazar, no eliminar, la segunda estrofa por la primera, de esta manera, España no se sentiría lastimada con el canto patrio ecuatoriano.

\section{I}

Indignados tus hijos del yugo

que te impuso la ibérica audacia, de la injusta y horrenda desgracia que pesaba fatal sobre ti, santa voz a los cielos alzaron, voz de noble y sin par juramento, de vengarte del monstruo sangriento, de romper ese yugo servil.

\section{II}

Los primeros los hijos del suelo que, soberbio; el Pichincha decora te aclamaron por siempre señora y vertieron su sangre por ti.

Licencia Creative Commons Atribución 4.0 Internacional (CC BY 4.0)

Revista Cátedra, 2(2), pp. 39-54, mayo-agosto 2019. e-ISSN: 2631-2875

https://doi.org/10.29166/catedra.v2i2.1655 
Dios miró y aceptó el holocausto,

y esa sangre fue germen fecundo

de otros héroes que, atónito, el mundo

vio en tu torno a millares surgir.

Además de este intercambio de estrofas, reemplazaron ciertas palabras que denunciaban la invasión de la corona española. Este cambio se propone como un intento por suavizar el lenguaje expuesto, pero esta mutilación mostraba un artificio que lejos de lograr este propósito evidenciaba más el espíritu transgresor del Himno.

De acuerdo con (Miño, 1995, pág. 158), los versos que se intentó cambiar fueron los siguientes:

\section{Tercera estrofa}

Letra original: "i al león destrozado se oía / de impotencia y despecho rugir

Propuesta de cambio: "alejándose altivo rugir"

\section{Cuarta estrofa \\ Letra original: "Cedió al fin la fiereza española," \\ Propuesta de cambio "Cedió al fin su bravura indomable"}

En 1948, después de un trabajo de investigación realizado por el padre Aurelio Espinoza Pólit, en el gobierno de Carlos Julio Arosemena Tola se oficializa el Himno y el 23 de noviembre se lo declara intangible (Miño, 1995, págs. 156-162). Mientras que en 1965, se instaura como día del Himno Nacional el 26 de noviembre.

Si bien el discurso de Mera apelaba a la reconciliación de quienes integraban la nación, él se reconocía como español en tierras americanas, pero también decía reconocer a América como su madre amadísima (Miño, 1995, pág. 156). Por lo que ambos espacios geográficos, históricos y sociales tienen cabida en su canto épico, sin embargo del valor de su trabajo, también es claro que preferiría sacrificar componentes de la cultura indígena como la religión o el desmedro del idioma kichwa en búsqueda de cimentar la idea de nación.

\section{Contribución de la educación al proceso de decoloniaje}

La colonialidad del ver, del saber, del pensar permanece arraigada de manera especial a las sociedades que devienen de un proceso histórico de coloniaje europeo, no cabe duda que estas invasiones marcaron las formas de ser de los habitantes de América, antes conocida como Abya Yala, esto se demuestra, en actitudes cotidianas como las formas de vestir, de hablar, de pensar, de escribir. Las diferentes formas de colonialidad permiten que el poder hegemónico se manifieste y perviva en los grupos marginados, a través de su elecciones de vida. Valdez el al. (2019), lo explican de esta manera:

La colonización trajo consigo una serie de variables negativas para la convivencia en lo que hoy se conoce como Latinoamérica, implicaciones filosóficas, políticas y territoriales que por más de 500 años que dejaron pertrechos en la mente de los habitantes latinos, como analiza Fallilone (2017): no se puede olvidar "la etapa de opresión y explotación, vividos durante la colonización y usurpación de nuestro suelo por medio de los europeos" (pág. 238). 
Si bien en parte se ponen de manifiesto las implicaciones de la invasión española, es preciso indicar que una de las más grandes preocupaciones de este episodio violento de la historia es el ataque hacia la cultura, hecho que en la actualidad no constituye un objeto de cuestionamiento, pues hay un velo que nubla estas nuevas formas de colonia "colonialidad del poder, que se origina con la invención de América, que instaura un nuevo patrón de poder global en el proceso de expansión del sistema mundo capitalista" (Guerrero, 2010, pág, 24). Entonces lo único que queda en claro, para las nuevas colonias, es asimilar que lo dictaminado por las minorías dominantes es válido y seguramente es lo que se debe hacer para lograr bienestar en función de los nuevos órdenes impuestos.

Esta forma de construir y comprender el sistema-mundo afianza la idea de estratificación social que legitima los roles sociales a través del sistema escolar, como lo menciona Molina (2016) "la escuela contribuye a reproducir la distribución del capital cultural, y colabora con ello a la reproducción de la estructura del espacio social” (pág. 947). De tal manera que los roles sociales estarían condicionados por el lugar de origen, la cultura, el poder adquisitivo y la raza. Condicionamientos que deja en evidencia la colonialidad del poder aún latente, al respecto Quijano (2000) asegura "En otros términos, raza e identidad racial fueron establecidos como instrumentos de clasificación social básica de la población” (pág. 202) y se perpetúan a través de los sistemas educativos.

Estas formas de colonialidad provienen de la hegemonía occidental que incluye a Europa en un primer término y que se ha expandido a Estados Unidos. Al respecto, Molina (2016) asegura:

No obstante, puertas adentro de las escuelas latinoamericanas y también en términos históricos, la cultura considerada legítima ha sido siempre la de las clases mejor posicionadas en el espacio social local, constituidas por los descendientes de los conquistadores europeos blancos. La "historia universal" enseñada es la historia que tiene a Europa (y luego a los Estados Unidos, durante el siglo XX) como centro (pág. 954).

Se consolida de esta manera la colonialidad del ser, del ver y pensar que pervive bajo el entramado que tejen los recientes colonizadores donde se anulan culturas para lograr homogenización. Al respecto, Bhabha (2002) señala "Siempre debemos mantener abierto un espacio suplementario para la articulación de conocimientos culturales que son adyacentes y adjuntos pero no necesariamente acumulativos, teleológicos o dialécticos" (pág. 200).

La nación se configura desde la diversidad y la articulación cultural, donde el diálogo con la otredad es relevante para vivir en armonía, uno de los principales legados de la cultura indígena. Para contrarrestar la homogenización, el rol de los intelectuales comprometidos, compréndase escritores y docentes, es nuclear por ser los creadores y difusores del pensamiento a través del lenguaje escrito. Cabe apuntar que las teorías decoloniales deberían constituir un eje dentro del pensamiento crítico de Latinoamérica.

Uno de los elementos clave en el nacimiento de la nación es la creación de sus símbolos, en ellos se busca identificación y unión de la sociedad. De esta manera resulta visionario y contestatario el trabajo de Juan León Mera en la creación del Himno Nacional del Ecuador, donde se lee la invasión, la colonia y la liberación, así como el legado indígena y la huella española en la concepción de la idea de nación ecuatoriana. Este Himno causó polémica, 
especialmente con los versos de la primera estrofa tanto en el siglo XIX como en épocas más recientes. Al respecto, Ayala Mora (2007) narra que:

Comenzaba un acto académico o político con el Himno Nacional, coreado por los asistentes... Luego del coro, cuando el mundo empezaba a cantar "Los primeros los hijos del suelo...", una voz ronca y enérgica entonaba con la misma música "indignados tus hijos del yugo..." Muchos pensaban que se trataba de un despistado, pero los que lo conocíamos nos enterábamos por este curioso medio que allí estaba Reinaldo Miño, empecinado en sostener que la canción patria no debía ser mutilada; que no se debió nunca dejar de cantar su primera estrofa" (pág. 97).

La reacción de Reinaldo Miño como intelectual comprometido va acorde con la postura decolonial, que denuncia mecanismos de poder impuestos por occidente donde se fracciona al ser humano para someterlo a partir del concepto de raza. Al respecto Guerrero (2010) argumenta

un acto de descolonización, nos preguntamos en consecuencia ¿no sería empezar a Corazonar ${ }^{3}$ las epistemologías construidas por occidente y que aún están presentes en nuestras prácticas académicas e intelectuales? (Guerrero 2010, pág. 41)

Entonces la labor de los intelectuales es ubicarse en los márgenes de la sociedad para trasgredir los estándares de la modernidad, que en la actualidad constituye la nueva colonia. De allí la importancia del decoloniaje como una práctica de buen vivir que surge como una filosofía de las minorías para aplicar el saber ancestral en las formas de vida cotidianas. Hacer pública esta forma de vida a través de las artes y de la educación es un reto que aún está en construcción para repensar al ser humano desde la integralidad.

\section{Conclusión}

La nación es un concepto voluble que ha alcanzado repercusiones excluyentes porque abarca elementos culturales que se sobreponen a otros. Este desmedro generalmente alcanza a las mayorías que se han visto sometidas a lo que impone el poder hegemónico en busca de lograr homogeneidad en las sociedades modernas.

Las naciones buscan símbolos que las identifiquen y que sean aceptados por quienes las conforman, si el Himno Nacional del Ecuador es una partida de nacimiento desde la intelectualidad a la nación ecuatoriana, es cuestionable el cambio de la letra a favor de España, ¿cómo se podía ser una nación si aún se mantenían lazos de dependencia hacia la corona española, hacia la cabeza del león, que Sucre pisaba en una estatua creada en su honor?

En esta creación inacabada y artificial llamada nación, los conflictos que se presentaron debido a la letra del Himno Nacional del Ecuador evidenciaron que la reciente nación

${ }^{3}$ Corazonar, término empleado por Guerrero (2010) para indicar "que el corazón no excluye, no invisibiliza la razón, sino que por el contrario, el Corazonar le nutre de afectividad, a fin de que decolonice el carácter perverso, conquistador y colonial que históricamente ha tenido”. (pág. 41) 
ecuatoriana no podía desligarse de su inventora. De allí desprende el pensamiento colonizado que aún pervive, quizá ya no hacia los invasores europeos, sino hacia nuevos organismos y otras naciones con las que se han generado otro tipo de dependencias.

La matriz colonial aún se mantiene y perpetúa a través de la educación, lo que deja en evidencia la colonialidad del ver, del saber, del pensar. La labor de los escritores es volver la mirada hacia el pensamiento decolonial para comprenderlo dentro del contexto actual y ponerlo en práctica en busca de la liberación de ataduras coloniales que aún se sostienen en la sociedad ecuatoriana. 


\section{Bibliografía}

Ayala Mora, Enrique. (2007). Reinaldo Miño, el legado de un luchador (1924-2006). En Procesos Revista Ecuatoriana de Historia. No. 26 Quito: Universidad Andina Simón Bolívar.

Bhabha, Homi. (2002). El lugar de la cultura. Buenos Aires: Editorial Manantial.

Buriano, Ana. (2009). La construcción historiográfica de la nación ecuatoriana en los textos tempranos en la nación y su historia. América Latina Siglo XIX. Diego Palacios (coord.). México: El colegio de México, pp.167-225.

Carrera, Beatriz, Ruiz Zara. (2016). Abya Yala Wawgeykuna. Artes, saberes y vivencias de indígenas americanos. Obtenido de https://www.upo.es/investiga/enredars/wpcontent/uploads/2017/03/Pr\%C3\%B3logo.pdf

Gellner, Ernest. (2001). Naciones y nacionalismo. Madrid: Alianza Editorial, pp. 77-88.

Guerrero, Patricio. (2010). Corazonar. Una antropología comprometida con la vida. Miradas otras desde Abya Yala para la decolonización del poder, del saber y del ser. Quito: Ediciones Abya Yala.

Harrison, Regina. (1996). Entre el tronar épico y el canto elegiaco, simbología indígena en la poesía ecuatoriana de los siglos XIX-XX. Quito: Ediciones Abya Yala.

Mellado, Luciana. (2008). Aproximaciones a una idea de nación: convergencias y ambivalencias de una comunidad imaginada. Obtenido de https://scielo.conicyt.cl/scielo.php?script=sci_abstract\&pid=S071822012008000100003\&lng=es\&nrm=iso

Mera, Juan León. (S. F). Ojeada -histórico Crítica sobre la poesía ecuatoriana. Quito: Publicaciones Ariel

Miño, Reinaldo. (1995). En torno al Himno Nacional. En Juan León Mera. Una visión actual. Julio Pazos Barrera (comp). Quito: Corporación Editora Nacional.

Molina, Mercedes. (2016). La sociología del sistema de enseñanza de Bourdieu: Reflexiones desde América Latina. Obtenido de http://www.scielo.br/pdf/cp/v46n162/19805314-cp-46-162-00942.pdf

Prieto, Mercedes. (2010). Los indios y la nación: historias y memorias en disputa en Celebraciones centenarias y negociaciones por la nación ecuatoriana, pp. 265-316

Quijano, Aníbal. (2000). Colonialidad del poder, eurocentrismo y América Latina. Obtenido de $\quad$ http://www.decolonialtranslation.com/espanol/quijano-colonialidad-delpoder.pdf

Rodríguez, Castelo, Hernán. (S. F.). Literatura Ecuatoriana. Quito: Publicaciones Ariel

Romano, Ruggiero. (1994) Algunas consideraciones alrededor de Nación, Estado (y Libertad) en Europa y América Centro-Meridional en Cultura e identidad nacional. Roberto Blancarte (comp.). México: Fondo de Cultura Económica, pp. 21-43. 
Traverso, Martha. (1998). La identidad nacional en Ecuador. Un acercamiento psicosocial a la construcción nacional. Quito: Ediciones Abya Yala.

Valdez, Orlando, Romero, Luis \& Gómez, Ángel. (2019). Matrices decolonizadoras en la comunicación para entablar un diálogo con Occidente. Sophia, colección de Filosofía de la Educación, 26(1), pp. 281-305.

Vallejo, Raúl. (2002). Juan León Mera. en Historia de las literaturas del Ecuador Volumen 3. Diego Araujo Sánchez (coord. ). Quito: Corporación Editora Nacional, pp. 208-254. 


\section{Autora}

GLENDA VIÑAMAGUA-QUEZADA Licenciada en Ciencias de la Educación Especialización en Letras y Castellano por la Pontificia Universidad Católica del Ecuador, Magíster en Estudios del Arte por la Universidad Central del Ecuador. Egresó de la Maestría en Literatura Ecuatoriana e Hispanoamericana de la Pontificia Universidad Católica del Ecuador.

Fue docente en la Universidad de las Fuerzas Armadas ESPE, en la Escuela Politécnica Nacional y en la Universidad UTE. Escribió para la Revista Anaconda Arte y Cultura, para la Revista Artes de Diario La Hora. Fue Correctora de Estilo en Revista Diplomacia del Ministerio de Relaciones Exteriores y en Diario La Hora. Participó como jurado de la Categoría Literatura en el "Sistema Nacional de Fondos Concursables para las Artes y Fondo Editorial” Organizado por el Ministerio de Cultura 